\title{
A Review of China's Technological Developments in the 20th Century
}

\author{
Mei Ping Leong ${ }^{1,}$, Poh Kiat Ng ${ }^{1, b}$, Kian Siong Jee ${ }^{1, c}$, Yue Hang Tan ${ }^{1, d}$, \\ and Darren Kai Shen Lee Le $^{1, \text { }}$ \\ ${ }^{1}$ Faculty of Engineering \& Technology, Multimedia University, Jalan Air Keroh Lama, 75450 \\ Malacca, Malaysia. \\ aalicemeiping@theiet.org, bpkng@mmu.edu.my, \\ cksjee@mmu.edu.my, ${ }^{\mathrm{d}}$ tan_hang2003@yahoo.com, ${ }^{\mathrm{e}}$ darrenlee_1993@hotmail.com
}

Keywords: China, technology, technological developments, twentieth century, review, space technology, atomic energy

Abstract. This paper presents a review of China's technological development in the 20th century. The purpose of the review is to study the major technological inventions achieved by China in the 20th century that has brought significant impact to China's technological development. In the 20th century, China has made great achievements in the field of space technology and also atomic energy. In space technology, China launched its very first satellite, Dong Fang1 (DFH1) (translated as Red East 1) and continued to improvise it in terms of performance in the field of spaceflight technology. In the same century, China also explored the area of atomic energy by building its very first nuclear-powered submarine, Chang Zheng 1 (translated as Long March 1). These technological developments achieved in the 20th century allowed China to be a step ahead of many other countries towards the advancement of technology. It is hoped that this review on China's influential role in the technological developments of the 20th century can be used as a useful references for other countries that wish to embark upon rapid and progressive technological developments.

\section{Introduction}

In the 20th century, China has achieved tremendous growth in various fields especially in technological development. Leaders in the 20th century had influenced the growth in technological development and made huge changes and revolution in not only the history of China but also the history of world. Among all the significant technological developments in China's history, China's research and development in atomic energy and spaceflight technology voted and emerged as the major technological development [1]. The usage of atomic energy in their nuclear-powered submarine, Chang Zheng 1 (translated as Long March 1) and the development of the series of satellites in China spaceflight technology are the main highlights to the advancement of China technological development in the 20th century. The rise of modern China to become the second largest economy in the world was made possible only through the success of the Chinese communist revolution in the mid-20th century. China's rise to global power began in 1949 with the removal of the entire parasitic financial, comprador and speculative classes who had served as the intermediaries for European, Japanese and US imperialists draining China of its great wealth [2]. China as the intermediaries has brought the country into a whole new level by playing as the central role for European, Japanese and also US imperialists and therefore, China achieved an influential position in the 20th Century with the capability to explore and excel.

This paper's goal is to review the positive growth in the China technology in the 20th century starting from 1949 and was known as New China. The paper also attempts to provide a review on the China's most influential technological development in the 20th century. To make the review manageable, the paper concentrates on two technological developments as voted to be most significant by the members of the Chinese Academy of Engineering (CAE) in China's technological history, spaceflight technology in earth resource satellites and atomic energy in nuclear-powered submarine [1]. 


\section{Literature Review}

Somewhere around the 20th century, an ancient yet progressive industrial giant began to emerge in East Asia. Bordered by the South China Sea to the southeast and by the East China Sea towards the east, it is a country where every spot in it has a mark of memories or silent histories. In is a land that has fascinated the world with its rich cultural heritage. This country, or this land, is China. China is not only known as the fourth largest country in the world but also as one of the world's oldest civilisations and home to a population of approximately 1.351 billion people with a history of revolution and internal turmoil.

While China's history is much more extraordinary from the rest of the world, China started the industrialisation process from scratch, 200 years later than Europe. New China was founded in 1949, after a century of humiliation and war [3]. The advanced technology establishment made by China in 20th century is highly related and contributed by the late Chairman Mao Zedong. The late Chairman Mao Zedong was also known as the "Maker of the Twentieth Century" [4]. His decision to explore atomic energy and space technology resulted to a great step forward in China's technological development timeline.

Back at the beginning of the new century, a ballot box entitled "Significant Achievements of Engineering Technology in China in the 20th Century" was sponsored and voted by the members of the Chinese Academy of Engineering (CAE) along with members from associations and societies under the China Association for Science and Technology. In the system, among 25 other significant proponents of development, China's research and development in atomic energy and satellites came out on top as the most significant proponent in China's technological development [1]. China's first satellite, Dong Fang 1 (DFH1)(translated as Red East 1) was successfully launched into outer space on 24 April 1970 [5], marking a major achievement for China in the history of spaceflight. This accomplishment made China the fifth country to successfully accomplish an independent spaceflight launch capability. Wei Long (2000) commend that the launch of the first artificial satellite had denoted an influential leap in achieving more entries into the "space age".

In the late 20th century, China even started to extend the knowledge of satellite technology by collaborating with Brazil in launching the remote sensing satellite, Ziyuan-1 (ZY-1) [5],with the term "Ziyuan" carrying the definition of "Resources". In the year 2000, Ziyuan-2 (ZY-2) was launched with the support of even more hi-tech equipment and facilities [6]. The state-of-the-art satellite technology in China shows that they have come a long way in regards to space technology. While ZY-1 was only capable of capturing a photographic picture to be sent down to Earth viacanisters, ZY-2 was able to relay its state-of-the-art digital pictures via radio transmissions to ground stations [5].

After some innovation and improvement done based on the very first ZY-1 built in the 20th century, the developments on the newly launched ZY-3 in 2012 presented capabilities that captured space remote-sensing images, reinforced security and augmented geographic information systems [7]. Such achievements in satellite technology are significantly contributed by the emergence of knowledgeable and dedicated engineers and scientists. Table 1 shows the summary of the launching year of the remote sensing satellites in China in the 20th century, as discussed in the preceding paragraphs.

Table 1: Summary of the launching year of the remote sensing satellites in China in the 20th century

\begin{tabular}{|c|c|}
\hline Satellite & Year launched \\
\hline Ziyuan-1 series & $1999[5]$ \\
\hline Ziyuan-2 series & $2000[6]$ \\
\hline Ziyuan-3 series & $2012[7]$ \\
\hline
\end{tabular}

A year after the launch of the first satellite into outer space in 1970, Chinese scientists and engineers successfully designed and constructed its very first nuclear-powered submarine, which was commissioned in August 1971 [8]. The name issued to the first nuclear-powered submarine 
was Chang Zheng 1 (No. 401), which is directly translated as Long March 1 (No. 401). The progress of completing the submarine was challenging due to the lack of technical, financial and human resources. Therefore, the Chinese submarine engineers had to spend another decade to overcome the design flaws of the submarine. In early 1974, a trial test-run was conducted with Chang Zheng 1 (No. 401) with the involvement of the navy [8].

The trial test-run was a huge success. Chang Zheng 1 (No. 401) commenced service in August 1974 [8]. The successful launch of the very first nuclear-powered submarine by the Chinese motivated them to further expand their innovation by building another four more submarines with continuing codes of 402, 403, 404 and 405 between 1977 and 1990. Of all the five submarines, the first two, 401 and 402 were retired from active service in the year 2000 while the other three submarines still remained in service according to Xinhua News Agency (2003). Based on the aforementioned paragraphs, Table 2 presents a summary of the launching year of the nuclearpowered submarines in China in the 20th century.

Table 2: Summary of the launching year of the nuclear-powered submarines in China in the 20 th century [8]

\begin{tabular}{|c|c|}
\hline Nuclear-powered submarine & Year launched \\
\hline Chang Zheng 1 (No. 401) & August 1971 \\
\hline Chang Zheng 1 (No. 402) & 1977 \\
\hline Chang Zheng 1 (No. 403) & 1983 \\
\hline Chang Zheng 1 (No. 404) & 1987 \\
\hline Chang Zheng 1 (No. 405) & 1990 \\
\hline
\end{tabular}

Chang Zheng 1 (No. 401) was also the first Han Class nuclear-powered attack submarine (Type 091) in China, which meant that the submarine was the first generation nuclear-powered submarine of Chinese navy. The lead submarines (401 and 402), which were based on the technology of the 1950s and 1960s, experienced noise and radiation problems. An article on China's state-of-the-art nuclear-powered submarine written in The Japan Times [9] shared that China was now close to having nuclear-powered submarines that are able to launch a new class of nuclear-tipped missile, known as the JL-2, with an approximate range of more than $7400 \mathrm{~km}$. In association to this, China also proclaimed a "no first use" policy from the very first day when the atomic bomb test was conducted. This policy stated that the development of these nuclear weapons is only for China's self-defence and safeguarding for national security purposes and it will never be the first to use nuclear weapons at any time or under any circumstances.

To ensure the ongoing improvement in China's technological development, in the late 20th century (1982 to be exact), the National Key Technologies Research and Development Program was adopted [1]. This was a well-planned program that included objectives and plans to improve China's technological development sustain the application and commercialisation of key technologies and enhance imported technologies. The important four of the eight areas of focus in the program involved strategic hi-tech research on information technology, agricultural technologies, traditional industries enhancement through informatisation and sustained environmental development. Another four input issues included basic scientific researches, the upgradeof scientific levels in the western region, personnel training basses and structural reformation in research bodies.

\section{Conclusion}

All in all, the progressive and persevering China engineers and scientists have set an excellent example for other countries in exploring and extending the knowledge and achievements for technological development. China's technological development has been moving fast and outputting hi-tech and innovative achievements and research outcomes compared to other countries. In retrospect, to rise and accomplish such massive and state-of-the-art technological achievements within a century was indeed a challenging task that the people of China unrelentingly embraced. 
The contribution by the Chinese engineering community in the 20th century is definitely influential and helpful as references for any nation that wishes to embark upon rapid and progressive technological developments. With the aid of the existing and explored technologies, China's efforts on technological developments today will be a role model for other countries and a catalyst for themselves to move forward towards the advancement of more innovations, upgrades, technology enhancements and experiments.

\section{References}

[1] Information on http://china.org.cn/english/scitech/49733.htm.

[2] Information on http://www.globalresearch.ca/china-rise-fall-and-re-emergence-as-a-globalpower/29644.

[3] X. Wu, How the Newly Built State Transformed the Old Society? The Mechanical Political Integration Policy and Its Impact in Mainland China, 1949-1958, Journal of Cambridge Studies, 8 (2006) 84.

[4] S. A. Schram, Makers of the Twentieth Century: Mao Zedong, Makers of the 20th Century, 31 (1981).

[5] Information on http://www.spacedaily.com/news/china-00u.html.

[6] D. Li, S. Cui, and S. Jiao, "China's Satellite Remote Sensing Technology and Its Application in 20th Century," presented at the 22nd Asian Conference on Remote Sensing, Singapore, 2001.

[7] Information on http://news.nost.org.cn/2013/02/china-no-longer-reliant-on-foreign-satelliteimages/.

[8] Information on http://www.bjreview.com.cn/nation/txt/2013-11/02/content_575743.htm.

[9] M. Richardson, "China's Nuclear Program Still Shrouded in Secrecy," in The Japan Times, ed. Japan, 2013. 